\title{
Free-radical cyclization approach to polyheterocycles containing pyrrole and pyridine rings
}

\author{
Ivan P. Mosiagin, Olesya A. Tomashenko, Dar'ya V. Spiridonova, Mikhail S. Novikov, \\ Sergey P. Tunik and Alexander F. Khlebnikov*
}

\author{
Full Research Paper \\ Address: \\ Saint Petersburg State University, Institute of Chemistry, 7/9 \\ Universitetskaya nab., St. Petersburg 199034, Russia \\ Email: \\ Alexander F. Khlebnikov* - a.khlebnikov@spbu.ru \\ * Corresponding author \\ Keywords: \\ arylation; pyridine; pyrrole; radical cyclization; tris(trimethylsilyl)silane
}

\author{
Beilstein J. Org. Chem. 2021, 17, 1490-1498. \\ https://doi.org/10.3762/bjoc.17.105 \\ Received: 05 May 2021 \\ Accepted: 11 June 2021 \\ Published: 23 June 2021 \\ Associate Editor: C. Stephenson \\ (C) 2021 Mosiagin et al.; licensee Beilstein-Institut. \\ License and terms: see end of document.
}

\begin{abstract}
A wide range of derivatives with new pyrido[2,1- $a$ ]pyrrolo[3,4-c]isoquinoline skeleton was synthesized by free-radical intramolecular cyclization of $o$-bromophenyl-substituted pyrrolylpyridinium salts using the (TMS) ${ }_{3} \mathrm{SiH} / \mathrm{AIBN}$ system. The cyclization provides generally good yields of pyrido[2,1-a]pyrrolo[3,4-c]isoquinoline hydrobromides having no additional radical-sensitive substituents. The free bases can be obtained from the synthesized hydrobromides in quantitative yield by basification at room temperature. The selectivity control of intramolecular arylation was achieved by replacing the halogen: the use of 1-(2-(ortho-bromophenyl)-4-(ortho-iodophenyl)pyrrol-3-yl)pyridinium bromide makes it possible to obtain a monocyclization product, and the bicyclization product from the dibromo derivative. The procedure is also applicable to obtain 3-arylpyrido[2,1- $a$ ]pyrrolo[3,2c]isoquinoline derivatives including 2-unsubstituted skeletons that are inaccessible via Pd-catalyzed cyclization.
\end{abstract}

\section{Introduction}

Polycyclic heteroaromatic molecules, which have a tunable electronic structure and excellent self-assembling properties, are highly desirable in materials science, especially in post-silicon electronics [1-4]. Though the remarkable progress in the synthesis of the polycyclic heteroarenes during the last two decades, further development of the existing methodologies is still required for broadening of the scope of polycyclic heteroaromatics available for various applications. Fused polyheteroarenes, containing a pyrrole moiety, are widely present in natural products and pharmacologically important agents and have a significant importance in the development of new materials useful for bioimaging applications and chemosensor systems [3-13]. Pyrroles with vicinal $o$-bromophenyl and heteroaryl substituents, which are readily accessible via reactions of the corresponding $2 \mathrm{H}$-azirines and phenacylcycloiminium ylides [14-19], are excellent precursors for various fused aza-heteroaromatics via metal-catalyzed arylation [1719]. We have recently successfully applied this approach to 
synthesize the new luminescent heterocyclic system pyrido[2,1a]pyrrolo[3,2-c]isoquinoline A [17], which turned out to be useful for bioimaging [13] and as a ligand for the preparation of luminescent metal complexes, $\mathrm{Au}(\mathrm{I})$ [20], Ir(III) [21] and Eu(III) [22] (Scheme 1). According to the calculations, the isomeric pyrido[2,1-a]pyrrolo[3,4-c]isoquinoline system $\mathbf{B}$ (Scheme 1) should have no less interesting photophysical properties [17], than skeleton A but its synthesis is still a challenge. In particular, attempts to assemble this framework using Pd-catalyzed intramolecular arylation of compounds $\mathbf{C}^{\prime}(\mathrm{X}=\mathrm{Br}, \mathrm{I})$ failed [17]. In this work, we report an effective method for the assembly of pyrido[2,1-a]pyrrolo[3,4-c]isoquinoline and related frameworks via a free radical cyclization of pyrrolylpyridinium salts.

\section{Results and Discussion}

Although the intramolecular free-radical cyclization is widely used for the synthesis of heteroaromatic compounds [23-26], only a few examples of the successful use of radical cyclization for the synthesis of pyrrole-containing fused heteroaromatics are known in the literature [23-30]. We initiated our study with the attempts to carry out the cyclization of 4-(2bromophenyl)pyrrole 1a under standard radical cyclization conditions (azobisisobutyronitrile $(\mathrm{AIBN}) / \mathrm{Bu}_{3} \mathrm{SnH}$ ), which previously had been successfully used for the cyclization of 2-bromophenyl-substituted pyrroles into 7-oxa-2a1azabenzo[b]-cyclopenta[ $p q]$ pleiadenes [30]. However, an attempt to use $\mathrm{AIBN} / \mathrm{Bu}_{3} \mathrm{SnH}$ for the cyclization of pyrrole 1a to compound 3a only led to a tarring of the reaction mixture, regardless of the temperature $\left(70-110{ }^{\circ} \mathrm{C}, \mathrm{MeCN}\right)$ and the protocol for mixing the reagents (Scheme 2). Luckily, 4-(2iodophenyl)pyrrole 2 gave under these conditions target heterocyclic skeleton 3a in 50\% yield (Scheme 2). Salt 3a was characterized by ${ }^{1} \mathrm{H},{ }^{13} \mathrm{C}$ NMR and HRMS, its structure was also confirmed by single-crystal X-ray diffraction analysis (Figure 1).<smiles>[R]c1nc2c3ccccc3c3ccccn3c-2c1[R]</smiles>

A<smiles>[R]c1ncc2c3ccccc3c3ccccn3c1-2</smiles><smiles>[R]c1[nH]c(-c2ccccc2Br)c(-[n+]2ccccc2)c1[R]</smiles><smiles>[R]C1=NC1=[C+]1C=CC=[N+](CC(=O)c2ccccc2Br)[C+]1Br</smiles>

D<smiles>[X]c1ccccc1-c1c[nH]c([R])c1-[n+]1ccccc1</smiles>
$C^{\prime}$<smiles>[X]c1ccccc1C1=NC1</smiles>

E

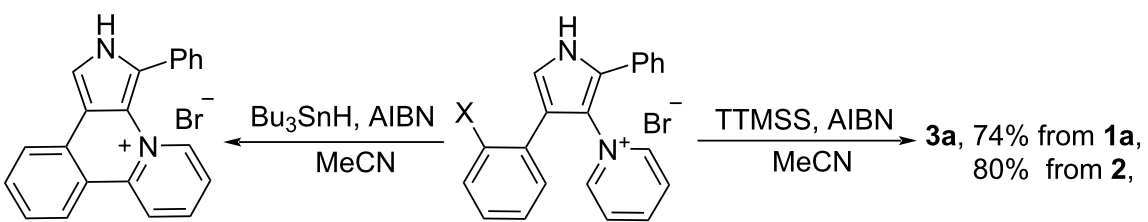

$3 \mathbf{a}, 0 \%$ from $\mathbf{1 a}$, $50 \%$ from 2<smiles>[X]c1ccccc1-c1cn(C)c(-c2ccccc2)c1-[n+]1ccccc1</smiles>

$N-B n-1 a, N-B n-2$, $N-A c-1 a, N-M e-1 a$ 1a, $X=B r ; 2, X=I$;

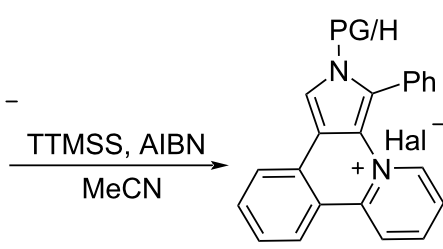

$3 a(54 \%$ from $\mathrm{N}-\mathrm{Ac}-1 \mathrm{a}), \mathrm{Hal}=\mathrm{Cl}$ N-Me-3a (PG = Me, 73\% from N-Me-1a), $\mathrm{Hal}=\mathrm{I}$ $N-B n-3 a(P G=B n, 67 \%$ from $N-B n-2)$, Hal $=\mathrm{Br}$ $N-B n-3 a(P G=B n, 64 \%$ from $N-B n-1 a)$, Hal $=\mathrm{Br}$ 


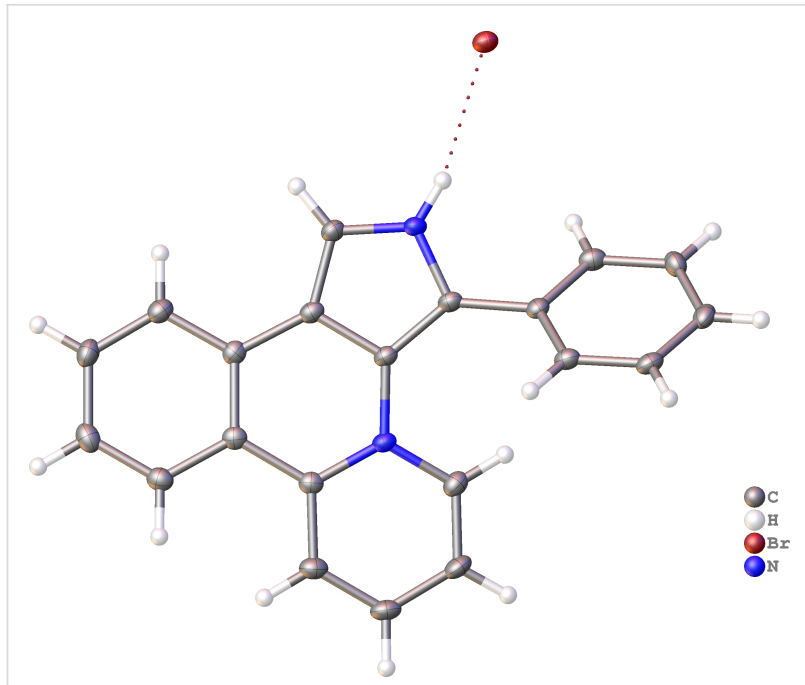

Figure 1: Molecular structure of compound 3a, displacement parameters are drawn at $50 \%$.

Since iodo-substituted compounds are more expensive and less accessible than bromo-substituted analogs, we tried to accomplish the cyclization of pyridinium salt 1a using another radical mediator, tris(trimethylsilyl)silane (TTMSS) [31,32], which, moreover, is much less toxic than tributylstannane. Fortunately, free-radical cyclization with TTMSS gave salt $\mathbf{3 a}$ in $74 \%$ yield from 4-(2-bromophenyl)pyrrole 1a, that is comparable with the yield for the 4-(2-iodophenyl)pyrrole 2 cyclization. Protection of pyrrole nitrogen with benzyl, methyl or acetyl PG did not improve the yield of the cyclization product 3a (Scheme 2). Acetylated compound $N$-Ac-1a gives deacetylated product 3a. The use of 1,1'-azobis(cyclohexanecarbonitrile) or $\mathrm{Et}_{3} \mathrm{~B}$ as radical reaction initiators instead of AIBN was unsuccessful.

Therefore, the reaction conditions for the free-radical cyclization of salt 1a were further optimized by variation of the mediator/initiator ratio, temperature, reaction time, concentration of 1a, and reagent mixing procedure (Table 1). The optimal conditions found (entry 8 , Table 1), characterized by the use of minimum amounts of reagents, were used to evaluate the substrate scope for the synthesis of compounds 3 (Table 2). The developed protocol doesn't require column chromatography for purification of target compounds $\mathbf{3}$ and can be performed in a gram scale.

Pyridinium bromides 1a-l,n-w and iodide $\mathbf{1 m}$ were prepared by the reaction of 3-(2-bromophenyl)-2H-azirine (4a) with substituted $N$-phenacyl pyridinium salts $5 \mathbf{a}-\mathbf{w}$ according to the published method (Table 2) [14]. The free-radical cyclization tolerates 4-F and 4-Cl substituents in the 2-phenyl ring (Table 2, entries 2,3), whereas the reaction of compound $\mathbf{1 d}$, with a 4-Br substituent in the 2-phenyl ring, led to the formation of a complex mixture of products because of competitive radical reactions. Methyl and methoxy substituents in the 2-phenyl ring (Table 2, entries 5-9) did not affect the cyclization, whereas the presence of 3- or 4- $\mathrm{NO}_{2}$-substituents (Table 2, entries 10 and 11) led to tarring of the reaction mixtures probably due to par-

Table 1: Optimization of the reaction conditions for the cyclization of 1a with TTMSS/AIBN in MeCN.

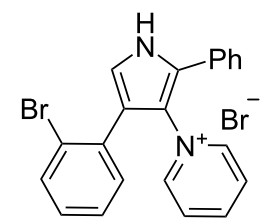

$1 \mathrm{a}$
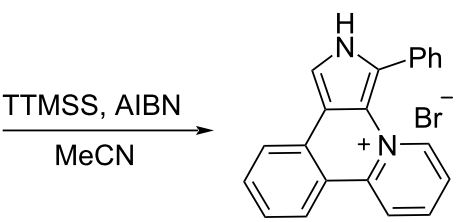

$3 \mathbf{a}$

\begin{tabular}{|c|c|c|c|c|c|}
\hline Entry & $\begin{array}{l}\text { TTMSS/AIBN, } \\
\text { equiv }\end{array}$ & $\begin{array}{l}T,{ }^{\circ} \mathrm{C}, \\
\text { (time, h) }\end{array}$ & $\begin{array}{l}\text { Concentration } \\
\text { of } 1 \mathrm{a}, \mathrm{mg} / \mathrm{mL}\end{array}$ & Reagent mixing procedure ${ }^{a}$ & Conversion ${ }^{b}$ of $\mathbf{1 a}$ to $\mathbf{3 a}, \%$ \\
\hline 1 & $3 / 3$ & $100(12)$ & 0.7 & $A$ & 20 \\
\hline 2 & $3 / 3$ & $100(12)$ & 10 & $A$ & 100 \\
\hline 3 & $3 / 3$ & $100(12)$ & 7 & $A$ & 100 \\
\hline 4 & $2 / 3$ & $100(12)$ & 7 & B & 100 \\
\hline 5 & $2 / 2$ & $100(6)$ & 10 & C & 100 \\
\hline 6 & $1.5 / 3$ & $100(5)$ & 10 & $\mathrm{C}$ & 100 \\
\hline 7 & $1.7 / 2.2$ & $85(5)$ & 10 & C & 100 \\
\hline 8 & $1.5 / 2$ & $75(25)$ & 10 & $\mathrm{C}$ & 100 \\
\hline
\end{tabular}

aMethod A: slow addition of the TTMSS/AIBN mixture through a syringe pump during all the reaction time; method B: slow addition of AIBN to the 1a/ TTMSS mixture; method $\mathrm{C}$ : heating of premixed mixture. ${ }^{\mathrm{b}}$ Conversion was determined by ${ }^{1} \mathrm{H}$ NMR. 
Table 2: Synthesis of compounds 1, 3 and 6 .

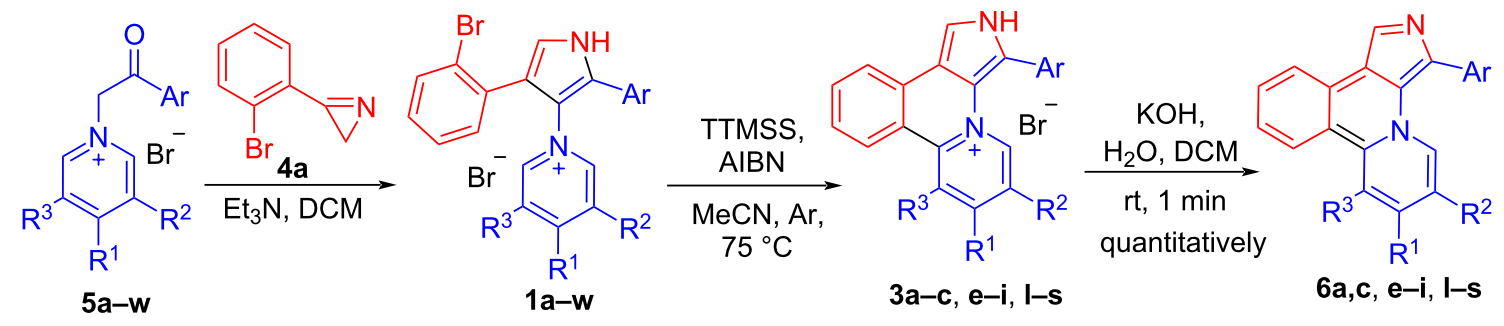

\begin{tabular}{|c|c|c|c|c|c|}
\hline Entry & $\mathrm{Ar}$ & $\mathrm{R}^{1}$ & $\mathrm{R}^{2}=\mathrm{R}^{3}$ & Yield of 1, \% & Yield of 3, \% \\
\hline 1 & $\mathrm{Ph}$ & $\mathrm{H}$ & $\mathrm{H}$ & a, 81 & a, 74 \\
\hline 2 & $4-\mathrm{FC}_{6} \mathrm{H}_{4}$ & $\mathrm{H}$ & $\mathrm{H}$ & b, 72 & b, 60 \\
\hline 3 & $4-\mathrm{ClC}_{6} \mathrm{H}_{4}$ & $\mathrm{H}$ & $\mathrm{H}$ & c, 80 & c, 71 \\
\hline 4 & 4- $\mathrm{BrC}_{6} \mathrm{H}_{4}$ & $\mathrm{H}$ & $\mathrm{H}$ & d, 79 & $-^{\mathrm{a}}$ \\
\hline 5 & $4-\mathrm{MeC}_{6} \mathrm{H}_{4}$ & $\mathrm{H}$ & $\mathrm{H}$ & e, 76 & e, 58 \\
\hline 6 & 4- $\mathrm{MeOC}_{6} \mathrm{H}_{4}$ & $\mathrm{H}$ & $\mathrm{H}$ & $\mathbf{f}, 83$ & $\mathbf{f}, 70$ \\
\hline 7 & $2-\mathrm{MeOC}_{6} \mathrm{H}_{4}$ & $\mathrm{H}$ & $\mathrm{H}$ & $\mathbf{g}, 63$ & $\mathbf{g}, 63$ \\
\hline 8 & $3-\mathrm{MeOC}_{6} \mathrm{H}_{4}$ & $\mathrm{H}$ & $\mathrm{H}$ & h, 68 & h, 74 \\
\hline 9 & $2,4-(\mathrm{MeO})_{2} \mathrm{C}_{6} \mathrm{H}_{3}$ & $\mathrm{H}$ & $\mathrm{H}$ & i, 56 & i, 93 \\
\hline 10 & $4-\mathrm{NO}_{2} \mathrm{C}_{6} \mathrm{H}_{4}$ & $\mathrm{H}$ & $\mathrm{H}$ & j, 72 & $-^{a}$ \\
\hline 11 & $3-\mathrm{NO}_{2} \mathrm{C}_{6} \mathrm{H}_{4}$ & $\mathrm{H}$ & $\mathrm{H}$ & $\mathbf{k}, 65$ & $-^{\mathrm{a}}$ \\
\hline 12 & $4-\mathrm{NCC}_{6} \mathrm{H}_{4}$ & $\mathrm{H}$ & $\mathrm{H}$ & $\mathrm{I}, 50$ & I, 73 \\
\hline 13 & 2-Pyridyl ${ }^{b}$ & $\mathrm{H}$ & $\mathrm{H}$ & m, 89 & m, 92 \\
\hline 14 & $\mathrm{Ph}$ & $\mathrm{Me}$ & $\mathrm{H}$ & n, 82 & n, 77 \\
\hline 15 & $\mathrm{Ph}$ & $\mathrm{MeO}$ & $\mathrm{H}$ & 0,55 & o, 72 \\
\hline 16 & $\mathrm{Ph}$ & $\mathrm{Me}_{2} \mathrm{~N}$ & $\mathrm{H}$ & $\mathbf{p}, 51$ & p, 85 \\
\hline 17 & $\mathrm{Ph}$ & $\mathrm{Ph}$ & $\mathrm{H}$ & $\mathbf{q}, 80$ & q, 53 \\
\hline 18 & $\mathrm{Ph}$ & 4- $\mathrm{MeOC}_{6} \mathrm{H}_{4}$ & $\mathrm{H}$ & $\mathbf{r}, 61$ & $\mathbf{r}, 71$ \\
\hline 19 & $\mathrm{Ph}$ & $\mathrm{H}$ & $\mathrm{Me}$ & s, 73 & s, 56 \\
\hline 20 & $\mathrm{Ph}$ & \multicolumn{2}{|c|}{$\mathrm{R}^{1}+\mathrm{R}^{2}=(\mathrm{CH}=\mathrm{CH})_{2} ; \mathrm{R}^{3}=\mathrm{H}$} & t, 40 & $-a$ \\
\hline 21 & $\mathrm{Ph}$ & $\mathrm{CO}_{2} \mathrm{Me}$ & $\mathrm{H}$ & $\mathbf{u}, 52$ & $-^{a}$ \\
\hline 22 & $\mathrm{Ph}$ & $\mathrm{CN}$ & $\mathrm{H}$ & $\mathbf{v}, 64^{c}$ & $-a$ \\
\hline 23 & $\mathrm{Ph}$ & $\mathrm{Bz}$ & $\mathrm{H}$ & $\mathbf{w}, 42^{\mathrm{C}}$ & $-a$ \\
\hline
\end{tabular}

${ }^{\mathrm{a}}$ Complex mixture of unidentified products. ${ }^{\mathrm{b}} \mathbf{1 m}, \mathbf{3 m}, \mathbf{5 m}$ - iodides

${ }^{\mathrm{C}} \mathrm{NiBr}_{2} \cdot 3 \mathrm{H}_{2} \mathrm{O}$ was used as a base instead of $\mathrm{Et}_{3} \mathrm{~N}$.

ticipation of the $\mathrm{NO}_{2}$ group in side radical reactions. The fact that this result is not related to the electron-withdrawing nature of this substituent follows from the fact that another strong EWG at the position 4, such as cyano, did not interfere with the reaction, and the product was obtained in good yield. (Table 2, entry 12). It is important that the reaction of iodide $\mathbf{1 m}$ with 2-pyridyl substituent gave a good yield of the product $\mathbf{3 m}$, which could be used for the preparation of bidentate ligand for metal complexes. Reaction of salts $\mathbf{1}$ with electron-donating para-substituents $\left(\mathrm{Me}, \mathrm{MeO}, \mathrm{Me}_{2} \mathrm{~N}\right)$ in the pyridine ring (1n-p,s) and aryl substituents (1q,r) afforded the corresponding compounds 3 in 51-82\% yield (Table 2, entries 14-19). Heating of isoquinolinium salt 1 t with the TTMSS/AIBN system, disappointingly, led to intensive tarring without the for- mation of the cyclization product in even trace amounts. Salts with electron-withdrawing para-substituents in the pyridine ring $(\mathbf{1 u}-\mathbf{w})$ do not cyclize under used reaction conditions. The reaction of $2 \mathrm{H}$-pyrido[2,1-a]pyrrolo[3,4-c] isoquinolin-4-ium bromides 3 with aq $\mathrm{KOH}$ at room temperature gave quantitatively the corresponding bases 6 (Table 2).

Pyridopyrroloisoquinolinium bromide 8, functionalized with an alkoxycarbonyl group at the $\mathrm{C} 1$ position, was also synthesized by the developed approach, starting from azirine $\mathbf{4 b}$ (Scheme 3).

Iodo-substituted salt 2 should be more reactive towards cyclization as compared to its bromo-analogue, and this can be used to 


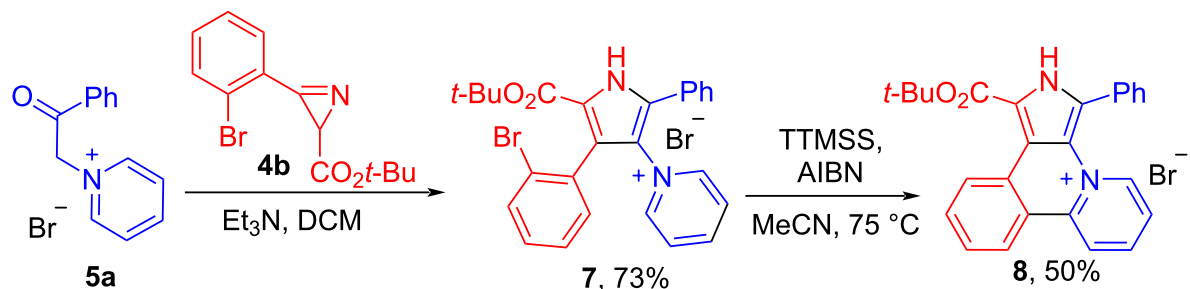

Scheme 3: Synthesis of $2 \mathrm{H}$-pyrido[2,1-a]pyrrolo[3,4-c]isoquinolin-4-ium bromide 8 .

control the selectivity of intramolecular arylation. Thus compound $\mathbf{1 0}$ was obtained from iodo/bromo-substituted salt 9 using 1.5 equiv of TTMSS. Dibromo-substituted salt 12 under the same conditions with 4 equiv of TTMSS gave the product of the double arylation, new heterocyclic skeleton $\mathbf{1 3}$, $1 H$-dibenzo[b,g]pyrido[2,1,6-de]pyrrolo[2,3,4-ij]quinolizin-14ium bromide (Scheme 4). The structure of $\mathbf{1 3}$ was confirmed by XRD-analysis (Figure 2). The reaction of bromide $\mathbf{1 3}$ with aq $\mathrm{KOH}$ at room temperature gave quantitatively the corresponding base 14. This new $24 \pi$-electron hexacyclic phenalenoid doped with two nitrogens is potentially useful material for organic field-effect transistors [1].

Bases 6 can be easily methylated and benzylated on the pyrrole nitrogen with formation of the corresponding salts $N$-Me-and $N$-Bn-3a in quantitative yield (Scheme 5).

Encouraged by the above mentioned results we decided to apply the developed methodology for the preparation of pyrido[2,1a]pyrrolo[3,2-c]isoquinoline derivatives $\mathbf{A}$ (Scheme 1). The pre-

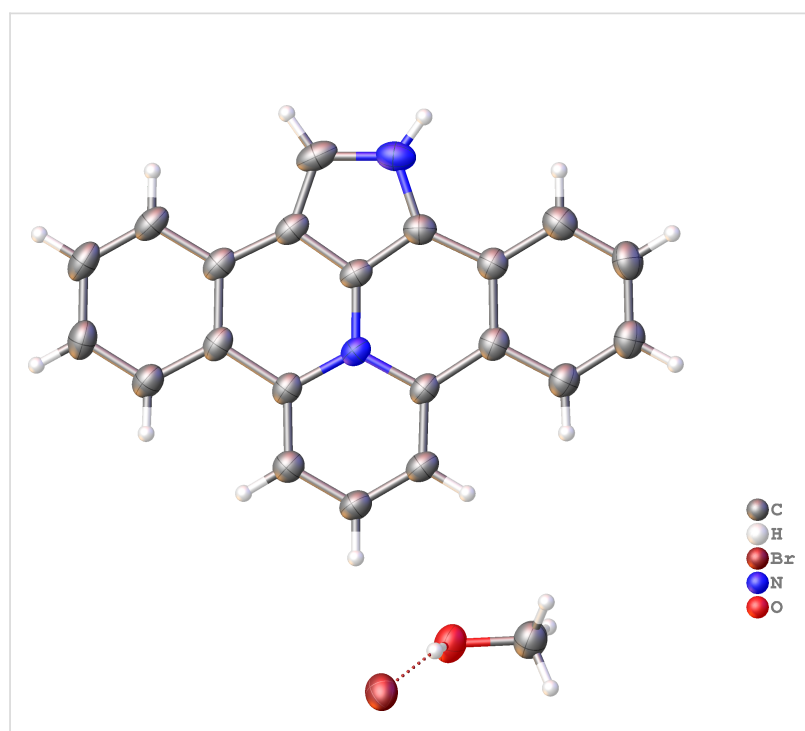

Figure 2: Molecular structure of compound 13, displacement parameters are drawn at $50 \%$ probability level.<smiles>Brc1ccccc1-c1[nH]cc(-c2ccccc2I)c1-n1cccc1Br</smiles>

9

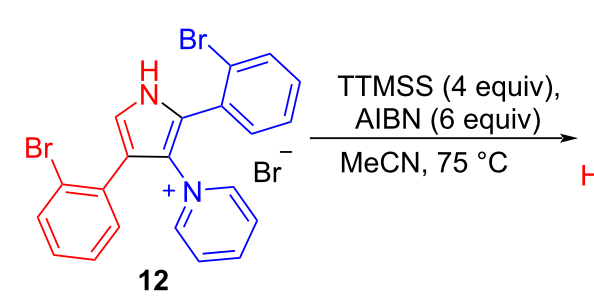

TTMSS ( 1.5 equiv), AIBN ( 2 equiv)<smiles>Brc1ccccc1-c1[nH]cc2c3ccccc3c3cccc[n+]3c12</smiles>

$10,58 \%$

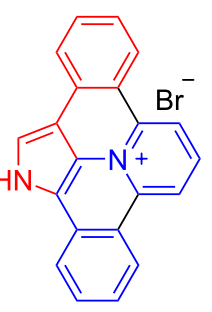

$13,74 \%$<smiles>Oc1ccccc1-c1ncc2c3ccccc3c3ccccn3c1-2</smiles>

$11,99 \%$ 


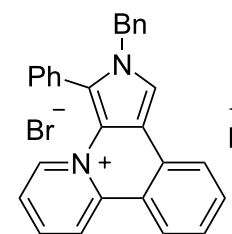

N-Bn-3a, $100 \%$

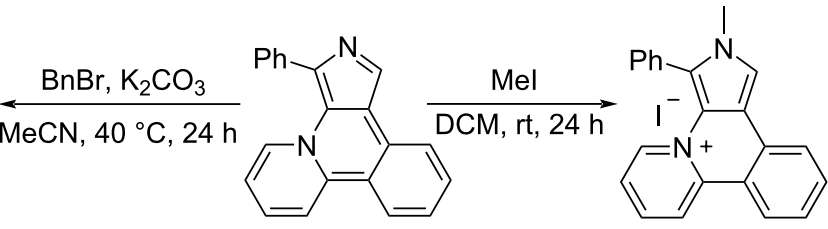

6 a
N-Me-3a, $100 \%$

Scheme 5: $N$-alkylation of the base $6 a$.

viously developed Pd-catalyzed protocol for the preparation of these compounds could be used only for arylation of pyrrole $N$-benzyl protected starting materials $\mathbf{C}$ [17]. The deprotection of the product could be performed only with $\mathrm{AlCl}_{3}$ under harsh conditions and, therefore, cannot be used for the preparation of compounds with acid-sensitive substituents. In addition, the debenzylation of 1-benzyl-3-arylpyrido[2,1-a]pyrrolo[3,2c]isoquinolines $\mathbf{A}$ was found to accompany by isomerization to 2-aryl derivatives, and therefore 2-unsubstituted bases A could not be prepared by a Pd-catalyzed procedure [17].

Optimal reaction conditions, found for the preparation of compounds 3 afforded reasonable results for the synthesis of 3-arylsubstituted heteroaromatics 17 (Table 3). The reaction tolerates various substituents $\left(\mathrm{H}, \mathrm{Me}, \mathrm{MeO}, \mathrm{Ph}, 4-\mathrm{MeOC}_{6} \mathrm{H}_{4}\right)$ at the pyridine moiety of $\mathbf{1 6}$, with the exception of electron-withdrawing groups (CN, Bz). The reaction of $1 H$-pyrido[2,1-a]pyrrolo[3,2$c$ ]isoquinolin-4-ium bromides $\mathbf{1 7 a}, \mathbf{a}-\mathbf{h}$ with $\mathrm{KOH}$ at room temperature gave quantitatively bases $\mathbf{1 8 a}-\mathbf{h}$.

The structure of $\mathbf{1 7 a}$ was confirmed by XRD-analysis (Figure 3).

It was found that both salt 17a and base 18a can be isomerized into isomer 19 under heating in the presence of $\mathrm{AlCl}_{3}$ via migration of the 3-Ph-group into the position 2 (Scheme 6).

Compounds 18a, 19 can be quantitatively $N$-alkylated by MeI at room temperature and by $\mathrm{BnBr}$ at $40{ }^{\circ} \mathrm{C}$ (Scheme 7).

A study of photophysical and electrochemical properties of compounds $\mathbf{3}$ is in progress and will be published elsewhere.

Table 3: Synthesis of compounds 16-18.<smiles>[R]c1c[n+](CC(=O)c2ccccc2Br)cc([R])c1[R]</smiles>

$15 a-g, i, j$<smiles>[R]c1c[n+](-c2c([Al])c[nH]c2-c2ccccc2Br)cc([R])c1[R]</smiles>

$16 a-j$

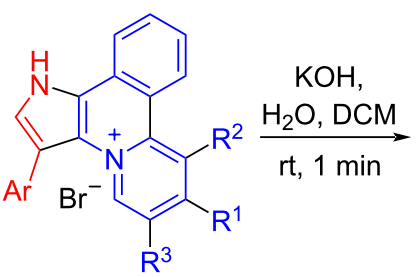

17a-h<smiles>[R]c1cn2c3c([Al])cnc-3c3ccccc3c2c([R])c1[R]</smiles>

18a, c-h, $99 \%$

\begin{tabular}{llllll}
\hline entry & $\mathrm{Ar}$, azirine & $\mathrm{R}^{1}$ & $\mathrm{R}^{2}=\mathrm{R}^{3}$ & Yield of 16, \% & Yield of 17, \% \\
1 & $\mathrm{Ph}, \mathbf{4 c}$ & $\mathrm{H}$ & $\mathrm{H}$ & $\mathbf{a}, 68$ & $\mathbf{a}, \mathbf{7 7}$ \\
2 & $\mathrm{Ph}, \mathbf{4 c}$ & $\mathrm{Me}$ & $\mathrm{H}$ & $\mathbf{b}, 64$ & $\mathbf{b}, 46$ \\
3 & $\mathrm{Ph}, \mathbf{4 c}$ & $\mathrm{MeO}$ & $\mathrm{H}$ & $\mathbf{c}, 48$ & $\mathbf{c}, 60$ \\
4 & $\mathrm{Ph}, \mathbf{4 c}$ & $\mathrm{Ph}$ & $\mathrm{H}$ & $\mathbf{d}, 53$ & $\mathbf{d}, 69$ \\
5 & $\mathrm{Ph}, \mathbf{4 c}$ & $4-\mathrm{MeOC}_{6} \mathrm{H}_{4}$ & $\mathrm{H}$ & $\mathbf{e}, 95$ & $\mathbf{e}, 46$ \\
6 & $\mathrm{Ph}, \mathbf{4 c}$ & $\mathrm{H}$ & $\mathrm{Me}$ & $\mathbf{f}, 35$ & $\mathbf{f}, 64$ \\
7 & $\mathrm{Ph}, \mathbf{4 c}$ & $\mathrm{R}^{1}+\mathrm{R}^{2}=(\mathrm{CH}=\mathrm{CH})_{2} ; \mathrm{R}^{3}=\mathrm{H}$ & $\mathbf{g}, 44$ & $\mathbf{g}, 49$ \\
8 & $4-\mathrm{MeOC} \mathrm{H}_{4}, \mathbf{4 d}$ & $\mathrm{H}$ & $\mathrm{H}$ & $\mathbf{h}, 50$ & $\mathbf{h}, 67$ \\
9 & $\mathrm{Ph}, \mathbf{4 c}$ & $\mathrm{CN}$ & $\mathrm{H}$ & $\mathbf{i}, 18^{\mathrm{a}}$ & - b \\
10 & $\mathrm{Ph}, \mathbf{4 c}$ & $\mathrm{Bz}$ & $\mathrm{H}$ & $\mathbf{j}, 45^{\mathrm{a}}$ & $-^{-}$ \\
\hline
\end{tabular}

${ }^{a} \mathrm{NiBr}_{2} \cdot 3 \mathrm{H}_{2} \mathrm{O}$ was used as a base instead of $\mathrm{Et}_{3} \mathrm{~N}$ (see Experimental section). ${ }^{b} \mathrm{C}$ omplex mixture of unidentified products. 


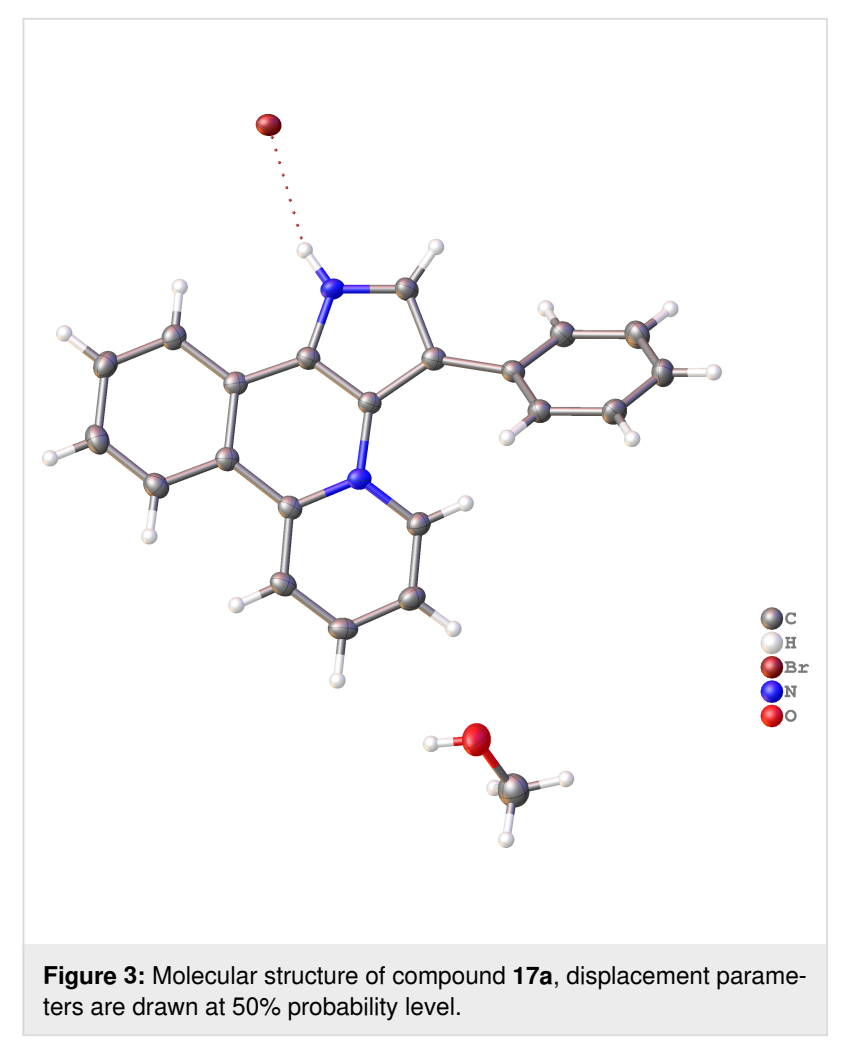

\section{Conclusion}

A wide range of derivatives with new pyrido[2,1-a]pyrrolo[3,4$c$ ]isoquinoline skeleton was synthesized by free-radical intramolecular cyclization of $o$-bromophenyl-substituted pyrrolylpyridinium salts using the TTMSS/AIBN system. The cyclization provides generally good yields of pyrido[2,1$a$ ]pyrrolo[3,4-c]isoquinoline hydrobromides having no additional radical-sensitive substituents. The developed protocol does not require column chromatography to purify target compounds and can be performed on a gram scale. The free bases can be obtained from the synthesized hydrobromides in quantitative yield by basification at rt. The use 2/4-(ortho-bromo/ iodophenyl)-substituted pyrrolylpyridinium bromides allows control over the chemoselectivity of the intramolecular arylation to give the monocyclization product starting from bromo/ iodo-substituents or biscyclization product starting from dibromo-derivatives to give the new $24 \pi$-electron hexacyclic phenalenoid doped with two nitrogens. The protocol is also applicable for the construction of the pyrido[2,1- $a$ ]pyrrolo[3,2c]isoquinoline backbone from $N$-unprotected pyrrolylpyridinium salts and, unlike the Pd-catalyzed version cyclization, avoids the deprotection step that is accompanied by isomerization.

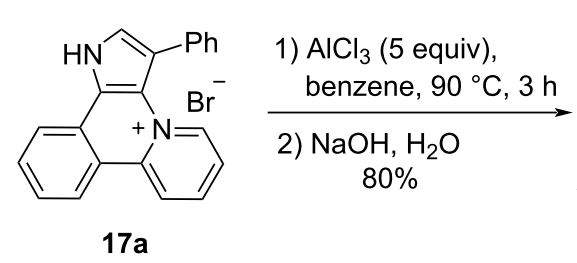

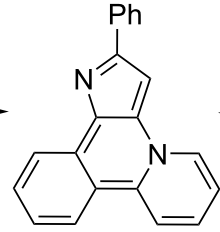

19
$\mathrm{AlCl}_{3}$ (5 equiv), benzene, $90{ }^{\circ} \mathrm{C}, 3 \mathrm{~h}$ $90 \%$

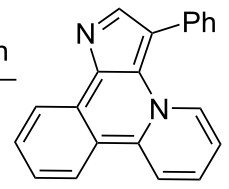

18a

Scheme 6: Isomerization of compounds $17 \mathrm{a}$ and $18 \mathrm{a}$

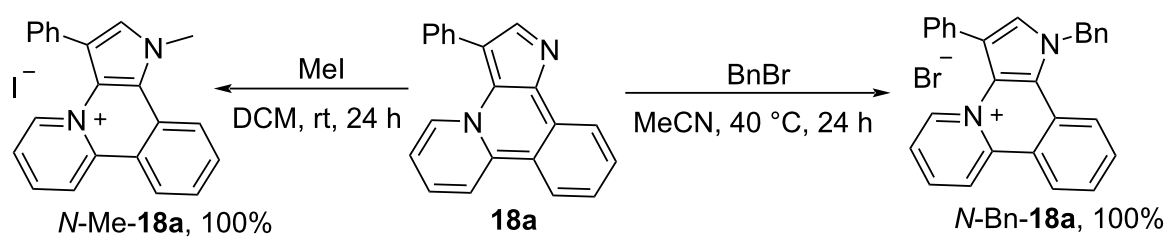<smiles></smiles>

19

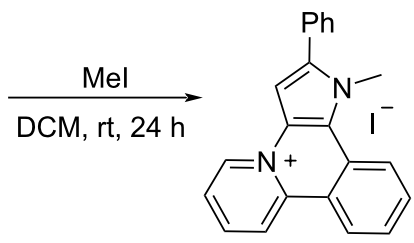

N-Me-19,100\% 


\section{Supporting Information}

\section{Supporting Information File 1}

Experimental procedures, compound characterization data, $\mathrm{X}$-ray diffraction experiment, and copies of NMR spectra of new compounds.

[https://www.beilstein-journals.org/bjoc/content/ supplementary/1860-5397-17-105-S1.pdf]

\section{Funding}

We gratefully acknowledge the financial support of the Russian Science Foundation project 16-13-10036. This research was carried out using resources of the Centre for Magnetic Resonance, the Research Centre for X-ray Diffraction Studies, the Centre for Chemical Analysis and Materials, and the Computer Centre of the Science Park of Saint Petersburg State University.

\section{ORCID ${ }^{\circledR}$ iDs}

Ivan P. Mosiagin - https://orcid.org/0000-0003-4658-8789 Olesya A. Tomashenko - https://orcid.org/0000-0002-9293-6548 Dar'ya V. Spiridonova - https://orcid.org/0000-0003-2823-0986 Sergey P. Tunik - https://orcid.org/0000-0002-9431-0944 Alexander F. Khlebnikov - https://orcid.org/0000-0002-6100-0309

\section{References}

1. Stępień, M.; Gońka, E.; Żyła, M.; Sprutta, N. Chem. Rev. 2017, 117, 3479-3716. doi:10.1021/acs.chemrev.6b00076

2. Lakshminarayana, A. N.; Chi, C. N-Containing Polycyclic Heteroarenes. In Polycyclic Arenes and Heteroarenes: Synthesis, Properties, and Applications; Miao, Q., Ed.; Wiley-VCH Verlag GmbH \& Co. KGaA: Weinheim, Germany, 2016; pp 225-249. doi:10.1002/9783527689545.ch9

3. Hou, Y.; Jiang, G.; Gong, J.; Sha, R.; Wang, J. Chem. Res. Chin. Univ. 2021, 37, 73-82. doi:10.1007/s40242-021-0396-Z

4. Zhen, X.; Qu, R.; Chen, W.; Wu, W.; Jiang, X. Biomater. Sci. 2021, 9 , 285-300. doi:10.1039/d0bm00819b

5. Wang, W.-W.; Wang, Y.; Wu, W.-N.; Zhao, X.-L.; Xu, Z.-Q.; Xu, Z.-H.; Li, X.-X.; Fan, Y.-C. Spectrochim. Acta, Part A 2020, 226, 117592. doi:10.1016/j.saa.2019.117592

6. Ren, F.; Shi, J.; Tong, B.; Cai, Z.; Dong, Y. Mater. Chem. Front. 2019, 3, 2072-2076. doi:10.1039/c9qm00372j

7. Leventis, A.; Royakkers, J.; Rapidis, A. G.; Goodeal, N.; Corpinot, M. K.; Frost, J. M.; Bučar, D.-K.; Blunt, M. O.; Cacialli, F.; Bronstein, H. J. Am. Chem. Soc. 2018, 140, 1622-1626. doi:10.1021/jacs.7b13447

8. Li, Y.; Luo, X.; Guo, Q.; Nie, Y.; Wang, T.; Zhang, C.; Huang, Z.; Wang, X.; Liu, Y.; Chen, Y.; Zheng, J.; Yang, S.; Fan, Y.; Xiang, R. J. Med. Chem. 2018, 61, 3166-3192. doi:10.1021/acs.jmedchem.8b00209

9. Santra, M.; Jun, Y. W.; Bae, J.; Sarkar, S.; Choi, W.; Gryko, D. T.; Ahn, K. H. Asian J. Org. Chem. 2017, 6, 278-281. doi:10.1002/ajoc.201600613
10. Ge, Y.; Liu, A.; Dong, J.; Duan, G.; Cao, X.; Li, F. Sens. Actuators, B 2017, 247, 46-52. doi:10.1016/j.snb.2017.02.157

11. Yu, C.; Wu, Q.; Wang, J.; Wei, Y.; Hao, E.; Jiao, L. J. Org. Chem. 2016, 81, 3761-3770. doi:10.1021/acs.joc.6b00414

12. Sareen, D.; Lee, J. H.; Hwang, H.; Yoo, S.; Lee, C.-H. Chem. Commun. 2016, 52, 5852-5855. doi:10.1039/c6cc01679k

13. Koshel, E. I.; Tomashenko, O. A.; Khlebnikov, A. F.; Gaginskaya, E. R.; Saifitdinova, A. F.; Tunik, S. P. Chromosome Res. 2016, 24 (Suppl. 1), 29-30. doi:10.1007/s10577-016-9532-x

14. Khlebnikov, A. F.; Golovkina, M. V.; Novikov, M. S.; Yufit, D. S. Org. Lett. 2012, 14, 3768-3771. doi:10.1021/ol3016594

15. Galenko, E. E.; Tomashenko, O. A.; Khlebnikov, A. F.; Novikov, M. S. Org. Biomol. Chem. 2015, 13, 9825-9833. doi:10.1039/c5ob01537e

16. Funt, L. D.; Tomashenko, O. A.; Khlebnikov, A. F.; Novikov, M. S.; Ivanov, A. Y. J. Org. Chem. 2016, 81, 11210-11221. doi:10.1021/acs.joc.6b02200

17. Tomashenko, O. A.; Khlebnikov, A. F.; Mosiagin, I. P.; Novikov, M. S.; Grachova, E. V.; Shakirova, J. R.; Tunik, S. P. RSC Adv. 2015, 5, 94551-94561. doi:10.1039/c5ra17755c

18. Tomashenko, O. A.; Novikov, M. S.; Khlebnikov, A. F. J. Org. Chem. 2017, 82, 616-623. doi:10.1021/acs.joc.6b02627

19. Funt, L. D.; Tomashenko, O. A.; Mosiagin, I. P.; Novikov, M. S.; Khlebnikov, A. F. J. Org. Chem. 2017, 82, 7583-7594. doi:10.1021/acs.joc.7b01341

20. Shakirova, J. R.; Tomashenko, O. A.; Grachova, E. V.; Starova, G. L.; Sizov, V. V.; Khlebnikov, A. F.; Tunik, S. P. Eur. J. Inorg. Chem. 2017, 4180-4186. doi:10.1002/ejic.201700731

21. Shakirova, J. R.; Tomashenko, O. A.; Galenko, E. E.; Khlebnikov, A. F.; Hirva, P.; Starova, G. L.; Su, S.-H.; Chou, P.-T.; Tunik, S. P. Inorg. Chem. 2018, 57, 6853-6864. doi:10.1021/acs.inorgchem.8b00390

22. Shakirova, J. R.; Shevchenko, N. N.; Baigildin, V. A.; Chelushkin, P. S. Khlebnikov, A. F.; Tomashenko, O. A.; Solomatina, A. I.; Starova, G. L.; Tunik, S. P. ACS Appl. Polym. Mater. 2020, 2, 537-547. doi:10.1021/acsapm.9b00952

23. Liao, J.; Yang, X.; Ouyang, L.; Lai, Y.; Huang, J.; Luo, R. Org. Chem. Front. 2021, 8, 1345-1363. doi:10.1039/d0qo01453b

24. Landais, Y., Ed. Free-Radical Synthesis and Functionalization of Heterocycles; Springer Int. Publ. AG: Switzerland, 2018. doi:10.1007/978-3-319-89521-5

25. Majumdar, K. C.; Basu, P. K.; Chattopadhyay, S. K. Tetrahedron 2007, 63, 793-826. doi:10.1016/j.tet.2006.09.049

26. Bowman, W. R.; Cloonan, M. O.; Krintel, S. L. J. Chem. Soc., Perkin Trans. 1 2001, 2885-2902. doi:10.1039/a909340k

27. Allin, S. M.; Bowman, W. R.; Elsegood, M. R. J.; McKee, V.; Karim, R.; Rahman, S. S. Tetrahedron 2005, 61, 2689-2696. doi:10.1016/j.tet.2005.01.064

28. Kotani, M.; Yamago, S.; Satoh, A.; Tokuyama, H.; Fukuyama, T. Synlett 2005, 1893-1896. doi:10.1055/s-2005-871931

29. Yamakawa, T.; Ideue, E.; Shimokawa, J.; Fukuyama, T. Angew. Chem., Int. Ed. 2010, 49, 9262-9265. doi:10.1002/anie.201004963

30. Petrovskii, P. P.; Tomashenko, O. A.; Novikov, M. S.; Khlebnikov, A. F.; Stoeckli-Evans, H. Chem. Heterocycl. Compd. 2017, 53, 909-912. doi:10.1007/s10593-017-2144-3

31. Chatgilialoglu, C.; Lalevée, J. Molecules 2012, 17, 527-555. doi:10.3390/molecules17010527

32. Castillo, R. R.; Burgos, C.; Vaquero, J. J.; Alvarez-Builla, J. Eur. J. Org. Chem. 2011, 619-628. doi:10.1002/ejoc.201001071 


\section{License and Terms}

This is an Open Access article under the terms of the Creative Commons Attribution License (https://creativecommons.org/licenses/by/4.0). Please note that the reuse, redistribution and reproduction in particular requires that the author(s) and source are credited and that individual graphics may be subject to special legal provisions.

The license is subject to the Beilstein Journal of Organic Chemistry terms and conditions:

(https://www.beilstein-journals.org/bjoc/terms)

The definitive version of this article is the electronic one which can be found at:

$\underline{\text { https://doi.org/10.3762/bjoc.17.105 }}$ 